\title{
Nutritional and hormonal factors control the gene expression of FoxOs, the mammalian homologues of DAF-16
}

\author{
M Imae, Z Fu, A Yoshida, T Noguchi ${ }^{1}$ and H Kato \\ Department of Applied Biological Chemistry, Graduate School of Agricultural and Life Sciences, University of Tokyo, Japan \\ ${ }^{1}$ Department of Biological Chemistry, College of Bioscience and Biotechnology, Chubu University, Japan \\ (Requests for offprints should be addressed to H Kato, Laboratory of Nutritional Biochemistry, Department of Applied Biological Chemistry, \\ Graduate School of Agricultural and Life Sciences, University of Tokyo, Yayoi 1-1-1, Bunkyo-ku, Tokyo, 113-8657, Japan; Email: \\ akatoq@mail.ecc.u-tokyo.ac.jp)
}

\begin{abstract}
Transcription factors of the FoxO family in mammals are orthologues of the Caenorhabditis elegans forkhead factor DAF-16, which has been characterized as a target of insulin-like signalling. Three members of this family have been identified in rodents: FoxO1, $\mathrm{FoxO} 3$ and $\mathrm{FoxO} 4$, originally termed FKHR, FKHRL1 and AFX respectively. A number of in vitro studies have revealed that FoxOs are regulated through phosphorylation in response to insulin and related growth factors, resulting in their nuclear exclusion and inactivation. To clarify the mechanisms involved in the regulation of these factors in vivo, we investigated in the present study whether or not, and if so how, their mRNA levels in rat liver respond to the stimuli of several nutritional and hormonal factors. Imposed fasting for $48 \mathrm{~h}$ significantly elevated mRNA levels of FoxO1 (1.5-fold), FoxO3 (1.4-fold), and FoxO4 (1.6-fold). Refeeding for $3 \mathrm{~h}$ recovered the induced mRNA levels of FoxO1 and FoxO3 to the control levels, but did not affect that of FoxO4. FoxO1 and FoxO4 mRNA levels were proved to be highly reflective of their protein levels measured by Western immunoblotting. Of the three $\mathrm{FoxO}$ genes, FoxO4 only showed altered levels of mRNA (a 1.5-fold increase) in response to a protein-free diet. Streptozotocin-induced diabetes for 28 days decreased hepatic mRNA levels of FoxO1 and FoxO3 and increased the level of FoxO4 mRNA, but short-term (7 days) diabetes had fewer effects on the expression of these genes. Insulin replacement partially restored the FoxO1 and FoxO4 mRNA levels, but had no effect on the FoxO3 mRNA level. Daily administration for 1 week of dexamethasone, a synthetic glucocorticoid, increased the mRNA levels of FoxO1 (1.8-fold) and FoxO3 (2.4-fold). These results show that the FoxO genes respond differently to nutritional and hormonal factors, suggesting a new mechanism for the regulation of FoxO-dependent gene expression by these factors. Moreover, changes of FoxO1 and FoxO4 in the nucleus in response to fasting also suggest that the regulation of nucleus/cytoplasm translocation actually functions in vivo.
\end{abstract}

Journal of Molecular Endocrinology (2003) 30, 253-262

\section{Introduction}

Members of the family of forkhead transcription factors are characterized by the presence of a highly conserved DNA-binding region, termed a winged helix/forkhead domain. More than 100 members of this family have been identified in species ranging from yeast to human. Each of these factors plays an important role in cell differentiation, embryogenesis, oncogenesis and metabolic regulation (Lai et al. 1993). DAF-16, a member of this family in Caenorhabditis elegans, has been demonstrated to be a major target of the insulin signalling pathway, whereby the insulin receptor signal affects the longevity of the animal through phosphatidylinositol 3-kinase (PI3K) and protein kinase B (PKB) (Ogg et al. 1997, Paradis \& Ruvkin 1998). In this respect, mammalian homologues of DAF-16 have also been speculated to be mediators of insulin action. Insulin up-regulates or downregulates a large number of genes (O'Brien et al. 2001). The down-regulated genes include 
insulin-like growth factor (IGF)-binding protein-1 (IGFBP-1), phosphoenolpyruvate carboxykinase (PEPCK), and glucose-6-phosphatase (G6Pase). Lines of evidence have shown that three DAF-16 homologues in mammals, FKHR, FKHRL1 and AFX (FoxO1, FoxO3 and FoxO4 respectively under the new nomenclature (Kaestner et al. 2000)), play essential roles in the suppression of these genes by insulin (Biggs et al. 1999, Brunet et al. 1999, Guo et al. 1999, Nakae et al. 1999, Takaishi et al. 1999), whereas Hall et al. (2000) reported that FoxO3 protein might have little or no role in the regulation of PEPCK gene expression in H4 IIE rat hepatoma cells. In the absence of insulin signal, these homologues bind to insulin-responsive elements in the promoter regions of the genes, resulting in transcription activation. The mechanism by which insulin suppresses the activities of FoxO proteins has been studied extensively using cell culture systems. Activation of the insulin receptor as well as the IGF-1 receptor causes phosphorylation of some serine/threonine sites in FoxO proteins, which in turn triggers their exclusion from the nucleus and confines them to the cytoplasm. The relevance of this mechanism in vivo, however, remains unclear.

In addition, the IGFBP-1 gene is up-regulated by glucocorticoid and protein malnutrition (Luo et al. 1990, Takenaka et al. 1993). We hypothesized that these factors might affect the status of one or more of the FoxO proteins. The present study was undertaken to obtain insight into (i) the mechanism of the actions of hormones and nutritional status through FoxO proteins, and (ii) the difference in the roles of three members of FoxO proteins in vivo. First, we cloned partial cDNAs for rat FoxOl, FoxO3 and FoxO4. Then we examined the effects of various conditions on their mRNA levels in the liver, one of the major target organs of insulin and the major expresser of FoxO genes. Next, we examined whether the changes in the mRNA levels of FoxOs were reflected in the whole lysate as well as the nuclear extracts of the liver of fasted rats. The results revealed that each member of the FoxO family is differentially regulated at the level of gene expression by hormones and nutritional status. Furthermore, the data obtained were highly suggestive of the existence of a mechanism in vivo by which the activities of FoxOl and FoxO4 are regulated by the intracellular localization of these proteins.

\section{Materials and Methods}

\section{Animals and experimental design}

Male Wistar rats with a mean body weight (BW) of $120 \mathrm{~g}$ were purchased from Charles River Japan (Kanagawa, Japan). The rats were kept in a room maintained at $22 \pm 1{ }^{\circ} \mathrm{C}$ on a $12 \mathrm{~h}$ light: $12 \mathrm{~h}$ darkness cycle (lights on at $0800 \mathrm{~h}$ ) and with free access to diet and water. The rats were given a $12 \%$ casein diet between 1000 and $1800 \mathrm{~h}$ for 3 days prior to being given the experimental diet. The three diets used in the experiments of this study were a $12 \%$ casein (12C) diet, a $12 \%$ gluten $(12 \mathrm{G})$ diet that is deficient in lysine and threonine, and a protein-free $(\mathrm{PF})$ diet, which were prepared as described previously (Takahashi et al. 1990). The experiments were designed to examine the effects of protein nutritional and hormonal factors on the expression of $\mathrm{FoxO}$ genes.

To study the effects of fasting, rats were fasted for $48 \mathrm{~h}$ (fasted group), or fed the 12C diet for $3 \mathrm{~h}$ after fasting for $45 \mathrm{~h}$ (refed group). Control rats were fed the 12C diet between 1000 and $1800 \mathrm{~h}$. Rats in all three groups were anaesthetized with pentobarbital and killed at $1800 \mathrm{~h}$, after which their livers were dissected out, frozen in liquid nitrogen, and stored at $-80{ }^{\circ} \mathrm{C}$ until use.

To analyse the effects of protein nutrition, rats were fed the $12 \mathrm{C}, 12 \mathrm{G}$ or PF diet between 1000 and $1800 \mathrm{~h}$ for 7 days. At $1130 \mathrm{~h}$ on day 8, five rats from each group were killed and their livers were sampled.

In experiments examining the effects of insulin deficiency, rats were injected with $75 \mathrm{mg} / \mathrm{kg}$ BW streptozotocin (STZ) (Sigma) dissolved in $50 \mathrm{mM}$ citrate buffer $(\mathrm{pH} 4.5)$ or the vehicle after an overnight fast. After 2 days, plasma glucose levels were measured to verify diabetic symptoms. To determine the short-term effects of insulin deficiency, three groups of ten diabetic rats each were respectively given $0.8 \mathrm{U} /$ day, $6.4 \mathrm{U} /$ day human insulin (Sigma) or vehicle s.c. once per day at $1000 \mathrm{~h}$ for the ensuing 7 days. The control group was also injected vehicle each day. Five rats from each treated group were fed either the $12 \mathrm{C}$ or the $\mathrm{PF}$ diet. Then, to determine the long-term effects of insulin deficiency, each group of five rats was given s.c. a daily injection at $1000 \mathrm{~h}$ of the vehicle or a dose of human insulin $(0.8 \mathrm{U} /$ day, or 3.2 $\mathrm{U} /$ day) for the following 28 days, and received the $12 \mathrm{C}$ diet throughout. On day 8 or 29 of the 
respective experiments, the rats were given their respective diets for $1.5 \mathrm{~h}$ after insulin treatment, then killed.

To analyse the effects of dexamethasone (DEX) (Sigma) treatment, ten rats were injected daily for 7 days at $1800 \mathrm{~h}$ with $1 \mathrm{mg} / \mathrm{kg}$ BW DEX dissolved in $40 \%$ ethanol $/ 60 \%$ PBS. Another ten rats were injected with the vehicle as the control group. Five rats from each group were then given the $12 \mathrm{C}$ or $\mathrm{PF}$ diet between 1000 and $1800 \mathrm{~h}$. On the 8th day, the liver was sampled as described above.

All experiments were performed under the guidelines of the Animal Usage Committee of the Faculty of Agriculture, University of Tokyo.

\section{Cloning of rat FoxO cDNAs}

cDNAs of rat FoxO1, FoxO3 and FoxO4 were obtained by RT-PGR. Sequences of the oligonucleotide primer pairs used for PGR amplification of the cDNA product of each gene were designed on the basis of the respective published mouse cDNA sequences. The primers for FoxOl were 5'-AACG AGCTCAAATGCTAGTACGATC-3' (sense) and 5'-CAGAAGGTTCTCAATGTTTTTCTGGA-3' (antisense), containing positions 1322-1499 of the mouse FoxOl cDNA (AF114258). The primers for FoxO3 were 5'-GGATGAGGTCGAGGATG ATG-3' (sense) and 5'-GAGCGCGGCTGCATAA GCCC-3' (antisense), containing positions 13211558 of the mouse FoxO3 cDNA (AF1 14259). The primers for $\mathrm{FoxO} 4$ were 5'-AAATGCCAGCCTC GGCGAGC-3' (sense) and 5'-GGCATTCGTCG CAGTAACAG-3' (antisense), containing positions 927-1284 of the mouse FoxO4 cDNA (AB032770). The PGR was carried out using AmpliTaq Gold polymerase (Perkin-Elmer, Branchburg, NJ, USA) in a Perkin-Elmer GeneAmp PCR system 9600. The FoxO PCR products were subcloned into a pGEM-T easy vector (Promega), and the sequences were confirmed using an automated DNA sequencer (ABI 310, Perkin-Elmer, Japan). The nucleotide sequences of rat FoxO1, FoxO3 and FoxO4 were compared with those of the mouse FoxOs, and the retrieved homology was 98, 92 and $96 \%$ with the corresponding region of the respective mouse sequences.

\section{RNase protection assay}

Total RNA was prepared from livers using TRIzol reagent (Invitrogen, Carlsbad, CA, USA). The quality and quantity of RNA samples were assessed by measuring the optical density of each sample at 260 and $280 \mathrm{~nm}$. An equal amount of total RNA $(40 \mu \mathrm{g})$ from each sample was then used to determine the mRNA levels of each target gene by means of an RNase protection assay described previously (Kato et al. 1994). In order to compare equivalent loading of RNA samples, rat GAPDH or fructose 2,6-bisphosphatase (F26BP) mRNA levels were used as internal controls to normalize the loading of total RNA amounts among treatments. Protected bands were imaged and analysed using FLA3000 (Fuji Photo Film, Tokyo, Japan). All mRNA levels are given as relative values in the experiment.

\section{Western immunoblotting}

Liver nuclear protein was extracted as described previously (Matsukawa et al. 2001). Liver lysate was prepared by homogenization of $0 \cdot 2 \mathrm{~g}$ liver in $2 \mathrm{ml}$ homogenization buffer $(50 \mathrm{mM}$ Hepes- $\mathrm{NaOH}, \mathrm{pH}$ $7 \cdot 6,2 \mathrm{mM}$ EDTA, $10 \mathrm{mM} \quad \mathrm{Na}_{3} \mathrm{VO}_{4}, 10 \mathrm{mM}$ $\mathrm{Na}_{4} \mathrm{P}_{2} \mathrm{O}_{7}, 100 \mathrm{mM} \mathrm{NaF}, 2 \mathrm{mM}$ phenylmethylsulphonyl fluoride, $100 \mathrm{kIU}$ aprotinin, and $2 \%$ Triton X-100), followed by centrifugation at $100000 \boldsymbol{g}$ for $1 \mathrm{~h}$, then the supernatant was stored at $-80{ }^{\circ} \mathrm{C}$ until use. Equal amounts of liver nuclear extract $(40 \mu \mathrm{g})$ or lysate $(100 \mu \mathrm{g})$ were separated by $10 \%$ SDS-PAGE gels, then transferred to nitrocellulose membranes. After incubation with the appropriate first antibody (FKHR(N-18) and AFX1(C-16) purchased from Santa Cruz Biotechnology, Santa Cruz, CA, USA) and horseradish peroxidase-coupled secondary antibody (Santa Cruz Biotechnology), the signal was visualized by enhanced chemiluminescence reagent and quantified with an LAS1000 plus imaging system (Fuji).

\section{Statistical analysis}

Values for the RNase protection assay and Western immunoblotting are expressed as the mean \pm S.E. The statistical significance was determined using one-way ANOVA, and post hoc analysis was performed using Fisher's protected least significant difference test (StatView J-4.51.1 for Macintosh; Abacus Concepts, Berkeley, CA, USA). Differences with $P$ values $<0.05$ were considered significant. 


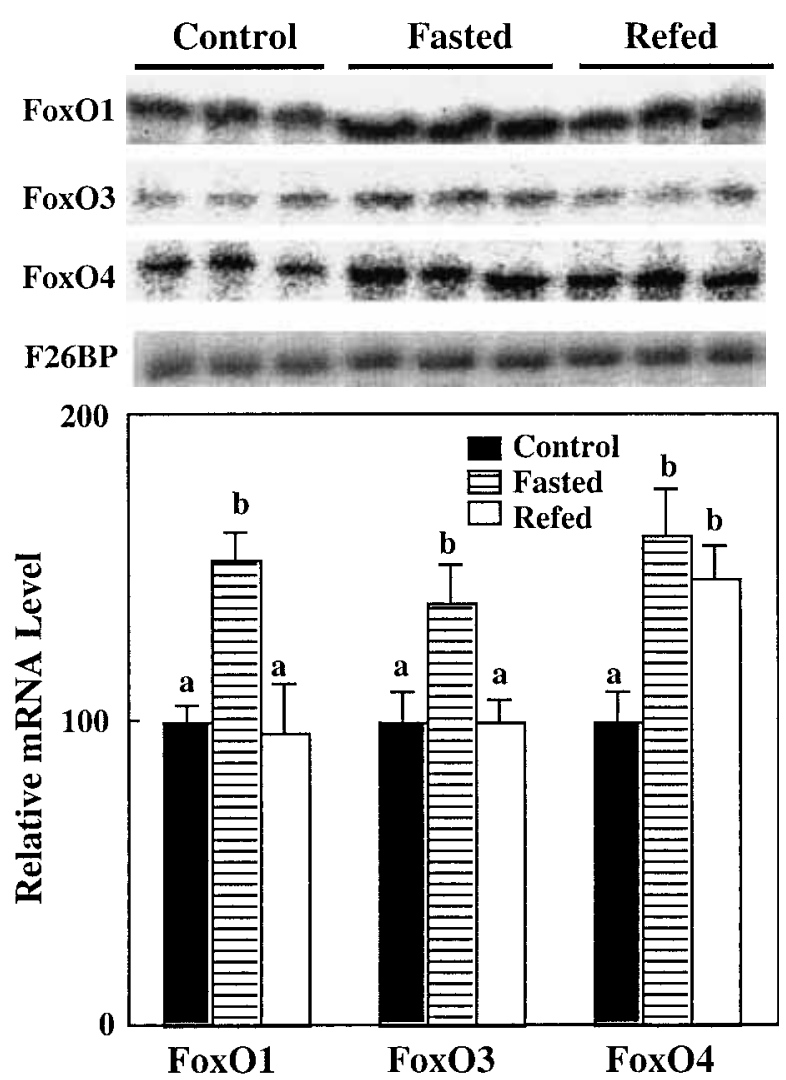

Figure 1 The effects of fasting and refeeding on FoxO gene expression in the liver. Rats were given a $12 \mathrm{C}$ diet for $8 \mathrm{~h}$ a day. Rats were continuously fed freely (control group), fasted for $48 \mathrm{~h}$ (fasted group), or refed $3 \mathrm{~h}$ after $45 \mathrm{~h}$ of fasting (refed group). The hepatic mRNA levels of FoxO and F26BP genes were determined by RNase protection assay. The representative bands of each gene are shown in the upper panel, and the data normalized by F26BP mRNA levels (means and S.E.M., $n=5$ ) are shown in the lower panel. Means not sharing the same letter are significantly different $(P<0.05)$.

\section{Results}

Figure 1 shows the effects of fasting and refeeding on hepatic mRNA levels of FoxO1, FoxO3 and FoxO4. Deprivation of food for $48 \mathrm{~h}$ caused significant increases in all FoxOs examined (1.5-fold for FoxO1, 1.4-fold for FoxO3 and 1.6-fold for FoxO4). The increased mRNA levels of FoxOl and FoxO3 recovered to control levels by a short refeeding of $3 \mathrm{~h}$, whereas the increased level of FoxO4 mRNA was not affected. Thus, the FoxO4 gene seems to require a longer time than the FoxOl or the FoxO3 gene for full recovery in response to refeeding.

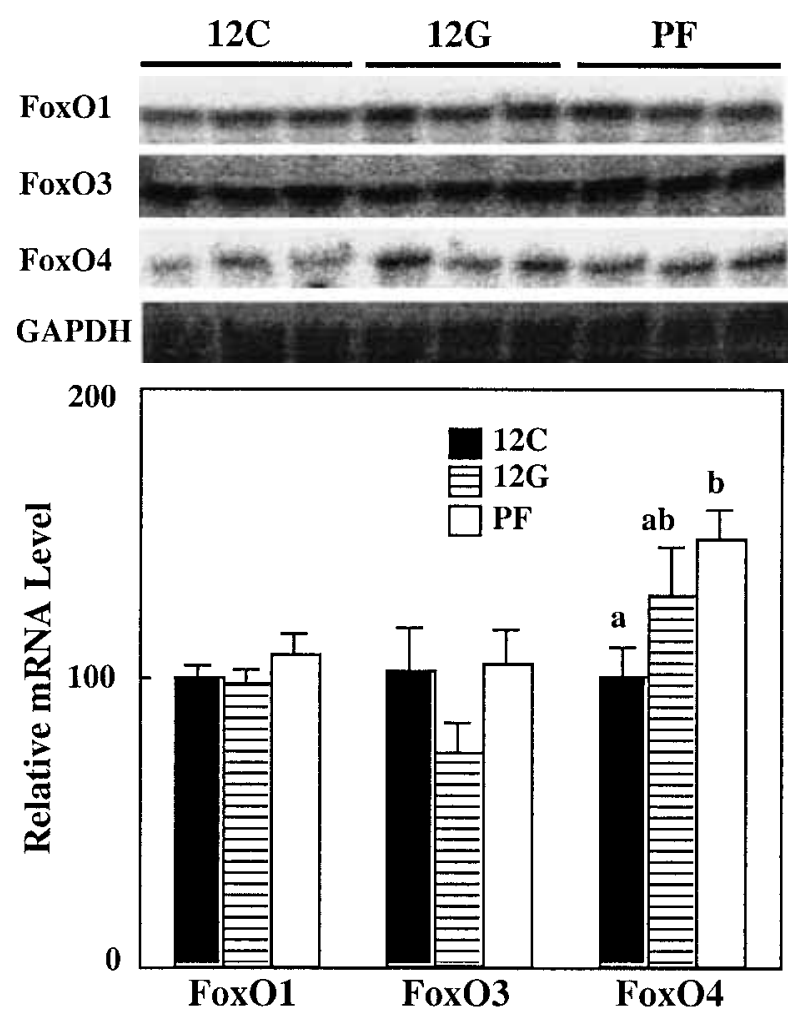

Figure 2 The effects of dietary protein on the hepatic mRNA levels of FoxOs. Rats were given a 12C, $12 \mathrm{G}$ or PF diet from 1000 to $1800 \mathrm{~h}$ for 7 days. On the 8th day, rats were fed their respective diets for $1.5 \mathrm{~h}$. The mRNA levels of FoxOs and GAPDH were determined by RNase protection assay. The representative bands of each gene are shown in the upper panel, and the quantitative representations of FoxOs normalized by GAPDH mRNA levels are shown in the lower panel (means and S.E.M., $n=5)$. Means not sharing the same letter are significantly different $(P<0 \cdot 05)$.

To investigate the effects of protein malnutrition on the expression of FoxO genes, we next fed the rats with either a $12 \mathrm{C}$, a $12 \mathrm{G}$ or a PF diet for 1 week, after which the hepatic mRNA levels of FoxOs were analysed (Fig. 2). The mRNA levels of FoxOl and FoxO3 were not affected by protein malnutrition, whereas that of FoxO4 in PF-fed rats was $50 \%$ higher than that in the $12 \mathrm{C}$-fed group. Feeding the $12 \mathrm{G}$ diet caused a small and statistically insignificant increase in FoxO4 mRNA level.

Although it is well known that one of the mechanisms by which insulin suppresses the expression of several genes is mediated by the translocation of FoxOs, other possibilities regarding the actions of insulin on FoxOs remain to be 
investigated. We therefore analysed the effects of insulin deficiency and its replenishment. Rats were made diabetic by injection of streptozotocin (STZ) 2 days prior to commencement of the experimental diet period (1 week), during which they were given daily injections of $0,0 \cdot 8$ or $6 \cdot 4 \mathrm{U}$ insulin. We previously observed that the same procedure of STZ treatment results in striking increases in rat liver in the mRNA levels of hepatocyte nuclear factor (HNF)-3 $\beta$ and $-3 \gamma$, which are also members of the forkhead transcription factor family, and that daily injection of $6.4 \mathrm{U}$ insulin abolishes these increases (Imae et al. 2000). As shown in Fig. 3A, insulin deficiency caused a 50\% decrease in FoxOl mRNA levels under both the $12 \mathrm{C}$ and PF diets, and these levels recovered only partially in response to a daily injection of insulin. A slighter effect was seen in the case of FoxO3 mRNA, which underwent a $40 \%$ decrease in response to STZ treatment only in rats fed the $\mathrm{PF}$ diet. FoxO4 mRNA level was not affected. Next, the effects of prolonged insulin deficiency were examined in rats that had received STZ treatment 4 weeks before the measurement of FoxO mRNAs (Fig. 3B). Four weeks of insulin deficiency caused further decreases in FoxO1 and FoxO3 mRNA levels, and only the former was restored by a single daily injection of insulin. In contrast, merely a slight increase in FoxO4 mRNA was observed in response to this prolonged insulin deficiency.

Among the array of genes that are controlled by glucocorticoids, many are also known to be regulated by nutrition and insulin. In this regard, the effects of glucocorticoids were examined in rats receiving a daily administration of DEX. The

Figure 3 The effects of the short-term (7 days) and long-term (28 days) diabetes and insulin treatment on the hepatic mRNA levels of FoxOs. Rats were injected with $75 \mathrm{mg} / \mathrm{kg}$ BW STZ and tested for plasma glucose 2 days after the injection. In the case of short-term diabetes $(A)$, rats were then given a $12 C$ or PF diet for 7 days as described in the legend to Fig. 2. During this 7-day period, STZ-injected rats were given $0,0.8$ or 6.4 $\mathrm{U}$ insulin at $1000 \mathrm{~h}$. In the case of long-term diabetes (B), they were then given a $12 \mathrm{C}$ diet for 28 days as described in the legend to Fig. 2. During this 28-day period, STZ-injected rats were given $0,0.8$ or $3.2 \mathrm{U}$ insulin at $1000 \mathrm{~h}$. Hepatic mRNA levels of FoxOs and F26BP were determined by RNase protection assay. Data normalized by F26BP mRNA levels (means and S.E.M., $n=5$ ) are shown. Means not sharing the same letter are significantly different $(P<0.05)$.
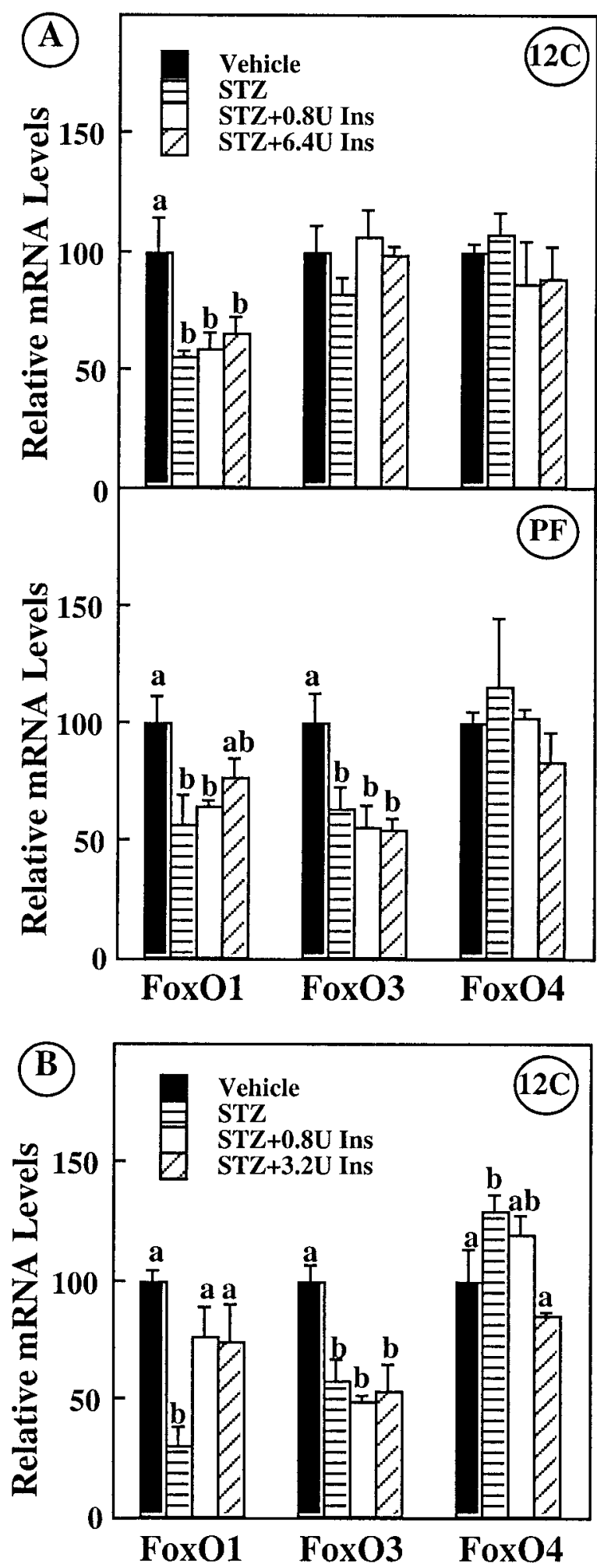

Journal of Molecular Endocrinology (2003) 30, 253-262 


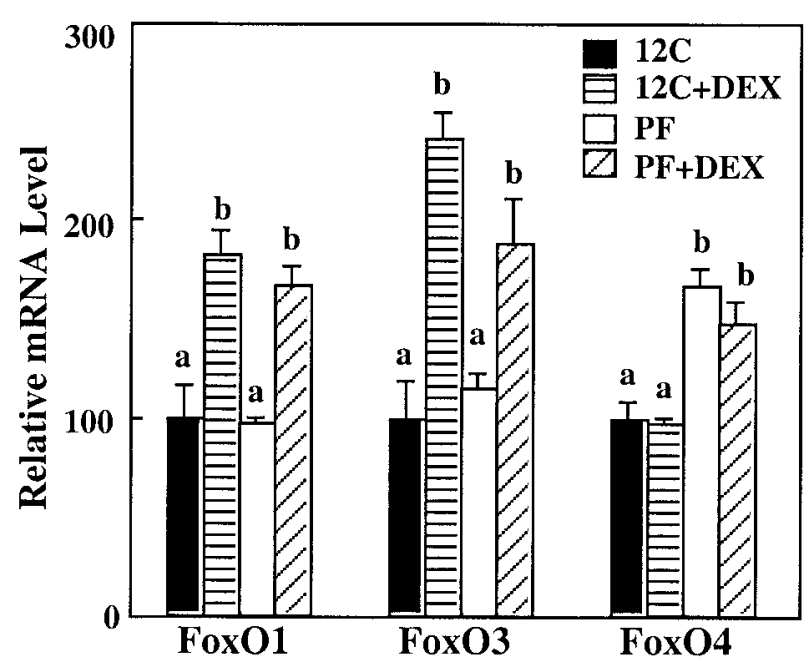

Figure 4 The effects of DEX treatment on the hepatic mRNA levels of FoxOs. Rats were given a $12 \mathrm{C}$ or PF diet for 7 days as described in the legend to Fig. 2 . During this 7-day period, $1 \mathrm{mg} / \mathrm{kg}$ BW DEX or vehicle was injected daily. The hepatic mRNA levels of FoxOs and GAPDH were determined by RNase protection assay. Data normalized by GAPDH mRNA levels (means and S.E.M., $n=5$ ) are shown. Means not sharing the same letter are significantly different $(P<0.05)$.
mRNA levels of FoxOl and FoxO3 increased by $1 \cdot 8$ - and 2.4-fold respectively in response to treatment with DEX, whereas that of FoxO4 was not affected (Fig. 4).

We next examined, by way of Western immunoblotting, whether the changes in mRNA levels were reflected in the protein levels of FoxOs. As a representative example of the results, the effects of fasting and refeeding are shown in Fig. 5. Fasting caused 1.5- and 1.4-fold increases in the liver of FoxOl and FoxO4 respectively, and the increase of FoxOl but not that of $\mathrm{FoxO} 4$ was abolished by refeeding for $3 \mathrm{~h}$ (Fig. 5A). The responses of these proteins were highly reflective of the changes in their mRNA levels (Fig. 1). In addition, when nuclear extract of the liver was used instead of the whole lysate, more drastic increases of FoxOl (2.8-fold) and FoxO4 (1·8-fold) were observed after starvation, and levels were almost completely returned to the control level by refeeding to that of the control (Fig. 5B). These results show that the relative distributions of FoxOs between the nucleus and cytosol change in response to feeding status. Despite intensive efforts, FoxO3

\section{A:Whole lysate}
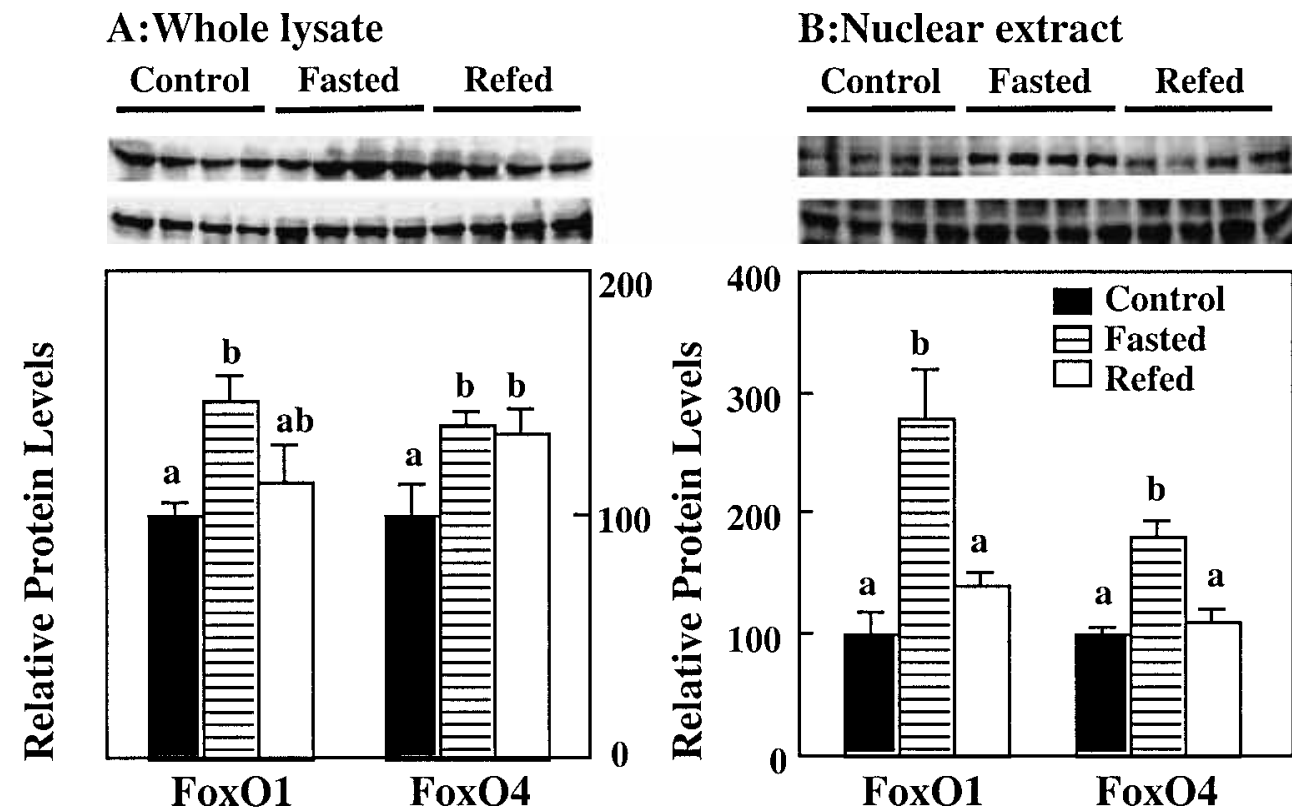

Figure $\mathbf{5}$ The effects of fasting and refeeding on FoxO protein levels in whole lysate and nuclear extract of the liver. Total extract $(A)$ or nuclear extract $(B)$ of the liver of rats used in the experiment described in Fig. 1 was prepared and subjected to Western immunoblot analyses using antibodies specific to FoxO1 and FoxO4. The bands of each protein are shown in the upper panel, and the quantitative representations are shown in the lower panel (means and S.E.M., $n=4$ ). Means not sharing the same letter are significantly different $(P<0.05)$. 
was not detected by commercially available antibodies. The level of this protein in the liver may be too low to measure by this method.

\section{Discussion}

Particular attention has recently been paid to the FoxO proteins, which are also referred to as the FKHR family or DAF-16 homologues, as transcription factors mediating the effects of insulin on a number of genes. Studies of mammalian FoxO proteins were ignited by a finding in the nematode C. elegans that DAF-16 is an essential component in the signalling pathway of insulin (Ogg et al. 1997, Paradis \& Ruvkun 1998). By means of genetic complementation studies, DAF-16 has been shown to be negatively controlled by a pathway consisting of DAF-2, AGE-1 and AKT, for which the mammalian counterparts are the insulin receptor, PI3K and PKB respectively. The mechanisms by which these pathways work in mammals and in nematodes are actually very similar, in that the insulin signal depresses the activities of DAF-16 and FoxOs by excluding them from the nucleus following phosphorylation of their serine/threonine sites (Biggs et al. 1999, Brunet et al. 1999, Guo et al. 1999, Takaishi et al. 1999).

Thus, a substantial part of the action of insulin on gene transcription is mediated by FoxOs; from a reverse viewpoint, the target genes of FoxOs are insulin-dependent and include many metabolically important genes such as IGFBP-1, tyrosine aminotransferase, PEPGK and G6 Pase. In the promoter region of these genes exist related sequence motifs, the consensus sequence being $\mathrm{T}(\mathrm{G} / \mathrm{A}) \mathrm{TT}(\mathrm{T} / \mathrm{G})(\mathrm{T} / \mathrm{G})$, which has been shown to be the binding motif of FoxOs and which is hence referred to as an insulin response sequence (IRS) or, more specifically, as a PEPCK-like motif (O'Brien et al. 2001). Although the mechanism for the regulation of these genes by FoxOs may seem very clearly defined, it should be noted that this pathway in mammals was deduced primarily from studies of cell culture systems in which wild-type or mutant FoxO was overexpressed. The way in which FoxOs regulate these genes in vivo remains unclear. The phosphorylation-dependent exclusion of FoxOs may thus be one of the major mechanisms of the regulation of this transcription factor family in mammals, but it is highly likely that other mechanisms are involved. Another question remaining unanswered is that of the differences in roles played by members of the FoxO family. To investigate these roles, we examined the effects of hormones and nutritional status on the expression of the genes corresponding to each member of the FoxO family in rat liver.

We showed that starvation for $48 \mathrm{~h}$ and protein malnutrition increased the expression of some FoxO genes. These changes probably contribute to the up-regulation of the genes that are positively regulated by energy restriction and protein malnutrition, such as IGFBP-1. In the case of protein malnutrition, the aberrant composition of plasma amino acids could be the primary cause of the up-regulation of FoxO4 mRNA. We have in fact observed that deprivation of amino acids from culture medium of HepG2 hepatoma cells results in an elevation of Fox04 mRNA (M Imae, Fu Z, Noguchi T \& Kato H, unpublished observations). It has been proposed that the signalling pathway triggered by amino acids includes activation of the mammalian target of rapamycin (mTOR), a pathway independent of PKB activation. In contrast, nuclear exclusion of FoxOs is induced by PKB, not by mTOR. Taken together, these findings indicate that protein and amino acid nutrition regulate FoxO4 activity at the level of gene expression, not at the level of translocation. An additional study by the authors is currently underway to prove this assumption.

As mentioned above, insulin-dependent suppression of gene expressions containing the PEPCKmotif has been studied extensively, focusing on the translocation of FoxOs. The results in Fig. 3 indicate that FoxO members are also regulated by insulin at the level of gene expression. The changes in FoxOl and FoxO3 in response to insulin deficiency were contrary to expectation, assuming that these factors up-regulate PEPCK-like genes. One possible explanation for this unexpected result would be that among the three FoxO genes, FoxO4 becomes the predominant regulator in an insulin-deficient state. It is also possible that the suppression of FoxOl and FoxO3 expression under the condition of insulin deficiency may serve to assuage the excessive actions of FoxOs.

A body of evidence has recently revealed a link between steroid hormones and FoxO activity. Serum- and glucocorticoid-induced kinases (SGKs) are a newly discovered family of kinases closely 
related to $\mathrm{PKB}$. SGK, whose gene expression is induced by glucocorticoids and other hormones and cytokines, has been shown to phosphorylate FoxOs with a different specificity to that of PKB. Furthermore, FoxOs interact with oestrogen receptors in a ligand-dependent manner and with other nuclear receptors independent of their ligands (Schuur et al. 2001, Zhao et al. 2001). These interactions have been demonstrated to alter the activity of FoxOs and of nuclear receptors. The up-regulation of FoxOl and FoxO3 genes by glucocorticoids (Fig. 4) adds another link between the nuclear receptor family and forkhead transcription factors. The induction of IGFBP-1, PEPGK and other genes by glucocorticoids could at least in part be mediated by an increase in FoxO mRNA levels.

In general, the results of the present study show that FoxOl and FoxO3 tended to respond to hormones and nutritional status in a similar manner, whereas the responses of FoxO4 differed. These findings suggest that FoxOl and FoxO3 share common physiological roles, whereas FoxO4 plays a different role. This finding on the differential regulation by hormones and nutrition of the members of a transcription factor family reinforces our previous observation that three members (HNF- $3 \alpha,-3 \beta$ and $-3 \gamma$, also termed FoxA1, FoxA2 and FoxA3) of the HNF-3 family, another subgroup of forkhead factors, exhibit various responses to the hormonal and dietary situations mentioned above (Imae et al. 2000). The target genes for HNF-3 include IGFBP-1 and PEPGK, and the potential HNF-3 binding sites exist in the promoters of these genes, which overlap the IRS (i.e. FoxO binding sites). In addition, the HNF-3 site of the IGFBP-1 promoter is part of a unit, which confers on this gene a responsiveness to amino acid insufficiency (Takenaka et al. 2000).

The physiological consequence of this FoxO mRNA regulation was not established in the present study. It should be noted, however, that small increases in DAF-16 have been associated with longevity in C. elegans, and that more robust activation results in growth arrest. Moreover, although overexpression of a FoxO in mammalian cells results in cell death, inhibition of FoxOs can also induce apoptosis. Thus, subtle changes in the levels of forkhead proteins within narrow ranges may be critical to their function (Nemoto \& Finkel
2002). In the present study, we also found that changes in the levels of FoxOl and FoxO4 proteins also varied within narrow ranges in response to food intake (Fig. 5), supporting the aforementioned hypothesis.

The mechanism for the regulation of FoxO gene expression has not yet been studied in detail. Analyses of the structure and function of the promoter of each member are therefore needed to delineate the mechanism mediating the effects of hormones and nutritional status on FoxO mRNA levels. In this regard, it should be noted that the activities of alternative promoters (DAF-16 $\alpha$ and DAF-16 $\beta$ ) of $d a f-16$ in the nematode, which dictate the production of different isoforms, are differentially regulated depending on the conditions (Lee et al. 2001). Additionally, Yang et al. (2001) recently demonstrated that a splice variant of FoxO4 (AFX zeta) with higher transcriptional activity is expressed in a tissue-specific manner, and is expressed abundantly in liver and kidney coincidently with IGFBP-1 expression. Although the FoxO4 mRNA levels determined in the present study correspond to the total of both transcripts, measurement of the amounts of the respective variants is of interest.

As discussed above, no previous study has addressed the relevance in vivo of the regulation of mammalian FoxO by its localization. We showed that FoxOs protein levels in both nuclear extract and whole lysate were increased by fasting (Fig. 5). The higher magnitude of increase in FoxOl and FoxO4 in the nuclear extract as compared with that in the whole lysate $(2 \cdot 8-$ vs $1 \cdot 5$-fold for FoxOl, and 1.8- vs 1.4-fold for FoxO4) suggests intracellular distributions of both factors are regulated such that the localization in the nucleus is preferable under the fasted condition. Not only the PKB but also other recently identified FoxO-directing kinases such as SGK and the dual-specificity tyrosine-phosphorylated and regulated kinase $1 \mathrm{~A}$ need to be studied in animal models, given that these new kinases are known to phosphorylate residues differently from the way PKB does (Brunet et al. 2001, Woods et al. 2001). The regulation of FoxO mRNA levels as presented here may represent the major regulatory mechanism of this family in vivo, or it may only play a role ancillary to that of translocation. To delineate the relative importance of these mechanisms, an additional systematic study, examining the mechanism under 
the condition of diabetes, illustrated in Fig. 5, and that under the conditions of protein malnutrition and glucocorticoid treatment respectively is underway. It should be noted that Richards et al. (2002) have recently shown that the expression of FoxO genes is regulated by several hormones in the ovary.

In conclusion, we herein proposed a new mechanism for the regulation of FoxO-dependent genes by hormonal and nutritional factors, a mechanism mediated by differential changes in FoxO gene expression.

\section{Acknowledgements}

This work was supported by a Grant-in-Aid for Scientific Research (No. 12460054) to H K from the Japan Society for the Promotion of Science and by support from the Program for the Promotion of Basic Research Activities for Innovative Biosciences.

\section{References}

Biggs WH III, Meisenhelder J, Hunter T, Cavenee WK \& Arden KC 1999 Protein kinase B/Akt-mediated phosphorylation promotes nuclear exclusion of the winged helix transcription factor FKHR1. PNAS 96 7421-7426.

Brunet A, Bonni A, Zigmond MJ, Lin MZ, Juo P, Hu LS, Anderson MJ, Arden KC, Blenis J \& Greenberg ME 1999 Akt promotes cell survival by phosphorylating and inhibiting a forkhead transcription factor. Cell 96 857-868.

Brunet A, Park J, Tran H, Hu LS, Hemmings BA \& Greenberg ME 2001 Protein kinase SGK mediates survival signals by phosphorylating the forkhead transcription factor FKHRL1 (FOXO3a). Molecular and Cellular Biology 21 952-965.

Guo SD, Cichy S, He XW, Cohen P \& Unterman TG 1999 Phosphorylation of serine 256 by protein kinase B disrupts transactivation by FKHR and mediates effects of insulin on insulin-like growth factor-binding protein-1 promoter activity through a conserved insulin response sequence. Fournal of Biological Chemistry 274 17184-17192.

Hall RK, Yamasaki T, Kucera T, Waltner-Law M, O'Brien R \& Granner DK 2000 Regulation of phosphoenolpyruvate carboxykinase and insulin-like growth factor-binding protein-1 gene expression by insulin. The role of winged helix/forkhead proteins. Fournal of Biological Chemistry 275 30169-30175.

Imae M, Inoue Y, Kato H \& Noguchi T 2000 Gene expression of the three members of hepatocyte nuclear factor-3 is differentially regulated by nutritional and hormonal factors. Fournal of Endocrinology 167 R1-R5.

Kaestner KH, Knochel W \& Martinez DE 2000 Unified nomenclature for the winged helix/forkhead transcription factors. Genes and Development 14 142-146.

Kato H, Faria TN, Stannard B, Roberts CT Jr \& LeRoith D 1994 Essential role of tyrosine residues 1131,1135 , and 1136 of the insulin-like growth factor-I (IGF-I) receptor in IGF-I action. Molecular Endocrinology 8 40-50.
Lai E, Clark KL, Burley SK \& Darnell JE Jr 1993 Hepatocyte nuclear factor 3 /fork head or 'winged helix' proteins: a family of transcription factors of divers biologic function. PNAS 90 10421-10423.

Lee RY, Hench J \& Ruvkun G 2001 Regulation of C. elegans DAF-16 and its human ortholog FKHRL1 by the daf-2 insulin-like signaling pathway. Current Biology 11 1950-1957.

Luo J, Reid RE \& Murphy LJ 1990 Dexamethasone increases hepatic insulin-like growth factor binding protein-1 (IGFBP-1) mRNA and serum IGFBP-1 concentrations in the rat. Endocrinology 127 1456-1462.

Matsukawa T, Inoue Y, Oishi Y, Kato H \& Noguchi T 2001 Up-regulation of upstream stimulatory factors by protein malnutrition and its possible role in regulation of the IGF-binding protein-l gene. Endocrinology 142 4643-4651.

Nakae J, Park BC \& Accili D 1999 Insulin stimulates phosphorylation of the forkhead transcription factor FKHR on serine 253 through a wortmannin-sensitive pathway. Foumal of Biological Chemistry 274 15982-15985.

Nemoto S \& Finkel T 2002 Redox regulation of forkhead proteins through a p66 shc-dependent signaling pathway. Science 29 2450-2452.

O'Brien RM, Streeper RS, Ayala JE, Stadelmaier BT \& Hornbuckle LA 2001 Insulin-regulated gene expression. Biochemical Society Transactions 29 552-558.

Ogg S, Paradis S, Gottlieb S, Patterson GI, Lee L, Tissenbaum HA \& Ruvkun G 1997 The fork head transcription factor DAF-16 transduces insulin-like metabolic and longevity signals in C. elegans. Nature $389994-999$.

Paradis S \& Ruvkun G 1998 Caenorhabditis elegans Akt/PKB transduces insulin receptor-like signals from AGE-1 PI3 kinase to the DAF-16 transcription factor. Genes and Development 12 2488-2498.

Richards JS, Sharma SC, Falender AE \& Lo YH 2002 Expression of FKHR, FKHRL1, and AFX genes in the rodent ovary: evidence for regulation by IGF-I, estrogen, and the gonadotropins. Molecular Endocrinology 16 580-589.

Schuur ER, Loktev AV, Sharma M, Sun Z, Roth RA \& Weigel RJ 2001 Ligand-dependent interaction of estrogen receptor- $\alpha$ with members of forkhead transcription factor family. Fournal of Biological Chemistry 276 33554-33560.

Takahashi S, Kajikawa M, Umezawa T, Takahashi S, Kato H, Miura Y, Nam TJ, Noguchi T \& Naito H 1990 Effect of dietary proteins on the plasma immunoreactive insulin-like growth factor-1/somatomedin C concentration in the rat. British Fournal of Nutrition 63 521-534.

Takaishi H, Konishi H, Matsuzaki H, Ono Y, Shirai Y, Saito N, Kitamura T, Ogawa W, Kasuga M, Kikkawa U et al. 1999 Regulation of nuclear translocation of forkhead transcription factor AFX by protein kinase B. PNAS 96 11836-11841.

Takenaka A, Hirosawa M, Mori M, Yamada S, Miura Y, Kato H, Takahashi S \& Noguchi T 1993 Effect of protein nutrition on the mRNA content of insulin-like growth factor-binding protein-1 in liver and kidney of rats. British Fournal of Nutrition $\mathbf{6 9}$ 73-82.

Takenaka A, Komori K, Morishita T, Takahashi SI, Hidaka T \& Noguchi T 2000 Amino acid regulation of gene transcription of rat insulin-like growth factor-binding protein-1. Fournal of Endocrinology 164 R11-R16.

Woods YL, Rena G, Morrice N, Barthel A, Becker W, Guo S, Unterman TG \& Cohen P 2001 The kinase DYRK1AS phosphorylates the transcription factor FKHR at Ser329 in vitro, a novel in vivo phosphorylation site. Biochemical fournal $\mathbf{3 5 5}$ 597-607.

Yang Z, Whelan J, Babb R \& Bowen BR 2001 An mRNA splice variant of the AFX gene with altered transcriptional activity. Journal of Biological Chemistry 277 8068-8075. 
Zhao HH, Herrera RE, Coronado-Heinsohn E, Yang MC, Ludes-Meyers JH, Seybold-Tilson KJ, Nawaz Z, Yee D, Barr FG, Diab SG et al. 2001 Forkhead homologue in rhabdomyosarcoma functions as a bifunctional nuclear receptor-interacting protein with both coactivator and corepressor functions. Fournal of Biological Chemistry 276 27907-27912.
Received 12 August 2002

Accepted 8 January 2003 